\title{
The Effectiveness of the Assignment of Dialogue with Shiah and Apostacy Groups via Facebook in the Coursework of Dakwah Information Technology
}

\author{
Muhamad Faisal Ashaari', Azimah Misrom², Badlihisham Mohd Nasir ${ }^{3}$ \\ Universiti Teknologi Malaysia, Johor, Malaysia \\ Correspondence: badlihisham@utm.my
}

\begin{abstract}
Nowadays, there are parties who deliberately spread doubts about Islam through the new media. Moreover, they attack Islam emotionally. Given that, students who pursue the course "Da'wah through Information Technology" in UKM are disclosed with those doubts and they are assigned to have dialogues with Shiite groups and apostate through Facebook. Indeed, the dialogue is a method of teaching and learning that can pass at least the third stage of Bloom Taxonomy and at the same time it can hone their skill of arguing. Students were asked to have dialogues with both groups to examine, to evaluate, to discuss, and to answer any doubt that they rise. This article discusses the findings of research on 50 students who pursue this course in Semester 1, 2013/14. The study found that this task really challenge the ability in arguing and students' knowledge. Although they have tried the best, many feel that they could not convince their dialogue partners. Throughout the course, they have been using various means to develop the existing knowledge mainly referring the problem to friends and teachers in order to defend the argument in the dialogue. Therefore, this assignment can pass at least the third level of Bloom's Taxonomy and they feel that this is a good assignment and should be resumed for the next semester. This study recommends appointing the instructor to guide students in managing dialog efficiently.
\end{abstract}

Keywords: dakwah; communication; technology and education 


\section{THE EFFECTIVENESS OF THE ASSIGNMENT OF DIALOGUE}

\section{PENDAHULUAN}

Kursus Teknologi Maklumat Dakwah merupakan salah satu subjek wajib di Jabatan Pengajian Dakwah dan Kepimpinan (JPDK) yang ditawarkan kepada pelajar yang berada pada semester 5. Ia menumpukan kepada metode dakwah yang berkesan dalam menyampaikan maklumat dan memberikan kesedaran Islam kepada masyarakat menerusi teknologi maklumat. Para pelajar bukan sahaja diajar secara teori tetapi secara praktikal bagi melengkapkan mereka dengan kemahiran dakwah menerusi maya. Kemahiran merupakan tacit knowledge yang sukar untuk dipindahkan menerusi penulisan mahupun percakapan tetapi memerlukan kepada pemahaman dan pelaksanaan serta latihan yang berterusan (Long Alex Lai, 2005). Justeru, kursus ini memerlukan kepada tumpuan yang berterusan terhadap aspek aplikasi agar kemahiran itu dapat digarap dan dimantapkan lagi.

Pendekatan pengajaran dan pembelajaran (P\&P) secara latihan yang berterusan ini membolehkan penguasaan pelajar terhadap sesuatu subjek dengan baik kerana mampu melepasi tahap ketiga Bloom Taxonomy iaitu application (aplikasi). Bloom mempunyai enam tahap bermula dengan knowledge (pengetahuan), comprehension (pemahaman), application (aplikasi), analysis (analisis), synthesis (sintesis) dan peringkat yang terakhir ialah evaluation (penilaian). Analisis merupakan tahap yang keempat yang sekiranya mampu dicapai, bererti P\&P yang telah dijalankan itu dianggap berkesan. Pada tahap ini, pelajar tidak sekadar mengetahui dan memahami sesuatu pembelajaran, tetapi dapat melaksanakannya. Pada tahap kelima pula, mereka juga dapat meluaskan lagi jangkauan kefahaman mereka, malahan boleh membuat rekacipta baru dan inovasi berdasarkan kepada konsep yang telah mereka pelajari. Pada tahap keenam pula, mereka dapat menilai tahap kefahaman dan penguasaan mereka terhadap kandungan kursus. Dengan ini, untuk memastikan keberkesanan sesuatu kursus, ia perlulah dapat mencapai sekurang-kurangnya tahap pertengahan Bloom Taxonomy.

Aktiviti amali secara online merupakan salah satu cara untuk mencapai tahap tersebut. Pelajar tidak sekadar memahaminya di dalam bilik kuliah, tetapi dapat meransang minda secara aktif dan membangunkan sendiri sesuatu kemahiran di alam maya. Menerusi aktiviti ini, pengajar dapat mengukur tahap pemahaman pelajar kerana sepanjang tugasan amali itu, pelajar akan berhadapan dengan penyesuaian ilmu teori dengan realiti yang boleh mengukuhkan lagi kefahaman terhadap sesuatu topik. Lebih dari itu, pengajar dapat menilai 


\section{THE EFFECTIVENESS OF THE ASSIGNMENT OF DIALOGUE}

sejauh manakah pelajar dapat menguasai sesuatu topik pembelajaran. Integrasi aktiviti amali dengan teori dakwah untuk membangunkan kemahiran telah dilakukan di dalam kursus “Teknologi Maklumat Dakwah". Antara tujuan kursus ini ialah untuk melatih para pelajar agar berani menampilkan diri dalam berdakwah secara maya. Dengan kehadiran media baharu, kursus ini telah memberikan tumpuan kepada dakwah menerusi facebook atau blog yang mengetengahkan dan membincangkan isu-isu semasa yang berkaitan dengan Islam.

Pendekatan tugasan amali di alam maya telah dilaksanakan sejak semester 1, 2012/13. Artikel ini akan membincangkan persepsi pelajar terhadap kelancaran tugasan yang diberikan, menganalisis aktiviti dan pola penggunaan media baharu untuk dialog, mengkaji kelestrian tugasan dialog secara maya.

\section{Kursus teknologi maklumat dakwah (PPPM 3033)}

Tujuan utama Teknologi Maklumat Dakwah ialah untuk memastikan pelajar dapat menggunakan medium maya sebagai salah satu cara untuk mengembangkan dakwah Islam pada masa kini. Ia juga bertujuan untuk memperkenalkan pelbagai cara, sumber dan perkhidmatan berdasarkan teknologi media baru bagi menyampaikan maklumat dakwah. Kursus ini turut membincangkan pengurusan teknologi maklumat, persembahan serta penyampaian maklumat dakwah Islam. Selain itu, aspek persembahan dan penyampaian maklumat dakwah secara terancang juga diketengahkan dengan menggunakan elemen multimedia dan interaktif. Ia juga turut membincangkan kesan globalisasi maklumat kepada metodologi dakwah serta menjelaskan cabaran, realiti masyarakat dan institusi Islam dalam penggunaan teknologi maklumat (Buku Panduan Pra-siswazah 2013).

Kursus ini diperkenalkan untuk melengkapkan pelajar dengan kemahiran komunikasi yang boleh mengembangkan lagi usaha dakwah menerusi maya. Perkembangan teknologi maklumat yang semakin pantas menjadikan kursus ini semakin relevan dengan keperluan semasa dan sebagai salah satu modul terpenting di jabatan ini khasnya. Ia diharapkan mampu untuk melahirkan modal insan bagi menampung sebahagian keperluan dakwah maya yang memerlukan kepada ramai lagi para pendakwah. Menerusi kursus ini, para pelajar dibimbing untuk membangunkan kreativiti dakwah dengan menggabungkan keupayaan akademik dengan kemahiran teknikal yang disasarkan boleh melepasi tahap ketiga Bloom Taxonomy 


\section{THE EFFECTIVENESS OF THE ASSIGNMENT OF DIALOGUE}

iaitu tahap application (aplikasi). Pada tahap yang ketiga ini, pelajar bukan sahaja mampu memahaminya sahaja tetapi mampu melaksanakannya. Sesuatu P\&P dianggap berkesan apabila pelajar mencapai keupayaan memberikan analisis dan pandangan terhadap hasil yang telah diusahakan bermula dengan tahap analysis (analisis), kemudian synthesis (sintesis) dan akhirnya evaluation (penilaian). Pencapaian melepasi tahap ketiga ini sangat penting bagi kursus ini kerana bukan hanya sekadar mempelajari teori sahaja tetapi mereka dilatih mengaplikasikannya.

Mana-mana kursus dakwah tidak dianggap mencukupi jika hanya dilakukan hanya secara teori sahaja kerana dakwah itu adalah sebuah pelaksanaan. Ia bukan setakat pembelajaran tentang kandungan dakwah, tetapi yang penting dari itu ialah penyesuaian kandungan dakwah dengan sasaran yang berbeza antara seorang dengan seorang yang lain. Setiap satu sasaran memerlukan kepada penyesuaian tersendiri yang perlu difikirkan oleh para pendakwah. Di sinilah terletaknya kebijaksanaan atau lebih dikenali dengan hikmah seperti yang disebut oleh al-Quran (al-Nahl: 125). Oleh itu, P\&P dalam bidang ini memerlukan kepada praktikal bagi mengasah kemahiran dalam menyampaikan dakwah. Antara hasil pembelajaran yang akan didapati oleh setiap pelajar yang mengambil kursus ini ialah :

1. Mengaplikasikan konsep dan teknik hikmah dakwah di dalam dunia siber menerusi penggunaan teknologi maklumat.

2. Menjelaskan kesan perkembangan teknologi dan lambakan maklumat terhadap Islam dan terhadap pegangan agama umat Islam.

3. Mengaplikasikan cara melaksanakan dakwah menerusi laman web, blog dan laman web sosial.

4. Mengaplikasikan cara untuk mencari, menyumbangkan dan membangunkan maklumat Islam di Internet.

Oleh yang demikian, kemahiran komunikasi dalam menyebarkan dakwah menerusi maya ini sangat penting untuk memastikan pengajaran mencapai tahap yang diperlukan dalam kursus Teknologi Maklumat Dakwah. Setiap pelajar mampu berbahas semula berkaitan untuk isu dakwah melalui internet atau maya.

\section{Dialog sebagai satu metode dakwah}

Dialog atau di dalam Bahasa al-Quran ialah jidal yang membawa maksud perdebatan. Ia diambil dari ayat al-Quran yang menjadi dasar dakwah di dalam surah al-Nahl, 125. Tetapi, 


\section{THE EFFECTIVENESS OF THE ASSIGNMENT OF DIALOGUE}

perdebatan di sini bukanlah perdebatan yang membawa kepada pertengkaran, caci maki dan sebagainya kerana ia diikat dengan perkataan "ahsan". Ia mestilah dengan cara yang terbaik kerana mungkin sahaja perbebatan itu membawa kepada perkelahian dan permusuhan. Al-Quran telah memahami tindakan manusia ini, maka dengan lebih awal lagi telah pun ditekankan perkara ini. Ia bukanlah hanya bersifat "hasan", tetapi "ahsan". Penggunaan metode "ahsan" ialah dengan cara menyebut persamaan dan membincangkan aspek perbezaan sehingga membawa perbezaan itu kepada aspek persamaan (al-Ghadban, 2011). Dengan ini, apabila pendakwah memberikan pandangan yang mungkin berbeza dengan nilai dan pegangan seseorang atau sekelompok masyarakat, dia mungkin akan ditentang sama ada secara sembunyi atau terus terang. Di sinilah terletaknya kebijaksanaan pendakwah dalam mengendalikan keadaan itu dan kalau boleh mengadakan dialog dengan orang yang menentang untuk mengetahui asas tentangan mereka.

Dialog merupakan tahap yang tertinggi dalam menjalankan dakwah. Ini ditegaskan di dalam al-Quran apabila Allah memulakan metode dakwah itu dengan hikmah, peringatan yang baik dan mujadalah bi al-ahsan. Ini bermakna, pendekatan perdebatan dengan cara yang terbaik itu merupakan jalan yang terakhir dalam kalau dilakukan, biarlah secara "ahsan". Ia perlu mampu untuk memberikan hujah balas yang lebih kukuh dan jelas serta dapat memuaskan hati umum. Dalam masa yang sama, ia mestilah tidak berlangsung dalam kaedaan yang boleh menimbulkan kebencian dan permusuhan tetapi dalam suasana yang harmoni. Oleh sebab itu, perdebatan tidak harus merendahkan pihak lawan, apatah lagi menghina dan mengejeknya kerana tujuan perdebatan ialah untuk menunjukkan kebenaran sesuai dengan nilai-nilai ajaran Islam. Biarpun mungkin ada yang tidak mahu langsung menerima sebarang pandangan, maka bersangka baiklah dengan dia dan anggaplah ia adalah cabaran bagi pendakwah. Mungkin dia tidak menerimanya buat masa ini, mungkin satu hari nanti dia akan terima jua.

Di dalam al-Quran berdebat dan berdialog merupakan cara yang penting dalam berfikir dan ia adalah cara mencapai kebenaran seperti yang ditunjukkan dalam kisah Nabi Ibrahim ketika dia berfikir tentang tuhan matahari, bulan dan bintang. Begitu juga kisah Malaikat yang berdialog dengan Allah tentang pelantikan manusia sebagai khalifah sedangkan mereka soalan merasakan jauh lebih baik dari manusia. Selain itu, pada zaman Yunani, berdebat ini 


\section{THE EFFECTIVENESS OF THE ASSIGNMENT OF DIALOGUE}

telah digunakan untuk menentukan kebenaran sesuatu perkara sebagaimana yang ditunjukkan oleh Socrates dan Aristotle. Oleh kerana ia merupakan suatu metode yang penting, mereka telah pun membangunkan cara berdebat yang sistematik untuk mengelak kesalahan dalam membuat keputusan.

Dari perspektif pengajaran dan pembelajaran, berdialog dan berdebat merupakan metode PnP yang berkesan untuk mengasah soft skill (Aclan, Aziz, Hashima, \& Valdez, 2016) kerana ia boleh untuk meransang kognitif pelajar. Dalam sebuah kajian berkaitan dengan debat secara maya, pendekatan debat Socrates telah digunakan untuk meningkatkan perbincangan maya, pemikiran kritis dan pembelajaran (Whiteley, 2014). Dari sudut yang lain pula, debat secara maya ini boleh dikategorikan sebagai "online collaborative learning" kerana ia adalah salah satu cara yang boleh meningkatkan teaching presence dalam maya. Terdapat kajian mendapati bahawa interaksi maya menerusi Facebook telah berjaya menghasilkan teaching presence (Annamalai, Tan, \& Abdullah, 2016). Ringkasnya, dialog maya hingga ke tahap perdebatan merupakan salah satu cara yang berkesan dalam PnP, namun ia tertakluk kepada pelajar dan juga bagaimanakah cara ia dijalankan.

\section{Perjalanan kursus teknologi maklumat dakwah (PPPM3033)}

Kursus Teknologi Maklumat Dakwah ini ditawarkan di JPDK sebanyak 3 jam kredit yang dijalankan menerusi kuliah selama dua jam dan satu jam tutorial. Di dalam kuliah, pelajar telah diberikan pengajaran tentang teori dan aspek yang berkaitan dengan dakwah maya manakala menerusi tutorial pula, pelajar dibimbing menjalankan praktikal dakwah maya. Tugasan ini ada yang diberikan secara secara individu dan ada yang secara berkumpulan untuk menilai cara mereka mempraktikkan teori yang dipelajari di dalam dunia maya. Pemberat penilaian pula dilakukan secara 60:40 dimana 60 adalah semasa peperiksaan akhir manakala 40 ialah aspek praktikal.

Aspek yang terpenting di dalam dakwah maya ialah untuk mengenalpasti isu-isu dakwah yang perlu untuk diketengahkan. Antara punca orang Islam tidak memanfaatkan teknologi komunikasi untuk tujuan dakwah ialah kerana mereka tidak tahu apa yang ingin ditulis. Satu-satunya sebab ialah mereka tidak melihat masyarakat dengan pandangan dakwah yang menyebabkan mereka tidak mampu untuk mengetahui penyakit yang berlaku dalam masyarakat. Muhamad Faisal \& Nur Adhwa (2012) telah menjelaskan aplikasi kaedah 


\section{THE EFFECTIVENESS OF THE ASSIGNMENT OF DIALOGUE}

newsworthiness dalam penulisan Facebook dakwah. Ia menjelaskan cara untuk memilih isu yang boleh mendapatkan tarikan pembacaan termasuk tontonan yang tinggi.

Pada semester 1, 2013/2014, seramai 50 orang pelajar JPDK yang mengambil kursus ini. Mereka telah diberikan tugasan untuk melakukan dialog dengan golongan Syiah dan Murtad. Mereka telah dibahagikan kepada tiga kumpulan di mana setiap satu kumpulan diminta membangunkan satu akaun Facebook. Setiap pelajar perlu mengambil bahagian menerusi akaun Facebook berkenaan untuk berdialog dengan golongan tersebut. Ia adalah tugasan secara individu biarpun dijalankan mengikut kumpulan kerana setiap individu akan menggunakan akaun yang sama untuk berdialog. Penilaian diberikan berdasarkan kepada kekerapan setiap pelajar mengadakan dialog dan kematangan hujah dan idea yang dilontarkan. Sebelum itu, pelajar telah diberikan contoh dialog dan panduan untuk menjawab pertanyaan pembaca yang boleh dijadikan panduan dalam mengendalikan dialog ini. Sekiranya mereka ada menghadapi masalah di dalam berdialog, mereka boleh mengajukan perbincangan itu di dalam kelas tutorial. Dengan ini, pelajar akan mengasah bakat dan kemahiran mereka dalam berdialog dengan orang yang mempunyai aliran yang berbeza.

Kemampuan yang baik di dalam dialog ini boleh membawa pelajar mencapai lebih dari tahap tiga Bloom Taxonomy. Sewaktu dialog, pelajar bukan sahaja menyampaikan ilmu, tetapi mereka mengolah ilmu yang mereka ada mengikut keadaan rakan dialog. Dengan cara ini, mereka bukan sahaja terus "copy and paste" sahaja tetapi mereka perlu faham (comprehension), menganalisis keadaan rakan dialog dan apa yang mereka ucapkan (analisys), membuat sintesis pandangan mereka (syntesis) dan akhirnya membuat penilaian terhadap keseluruhan dialog yang dijalankan (evaluation). Ke semua keseluruhan kemahiran ini digarapkan berdasarkan kepada penguasaan mereka terhadap ilmu Islam itu sendiri yang bukan sahaja diperolehi sepanjang pengajian di universiti ini, bahkan mungkin juga asas ilmu Islam yang diperolehi sebelum dari menyertai universiti ini lagi. Kursus ini membantu untuk menajamkan lagi kemahiran mereka sebagai pendakwah dalam berkomunikasi secara maya.

\section{METODE KAJIAN}

Kajian ini ialah kajian kualitatif yang dijalankan menerusi soal selidik kepada keseluruhan 50 orang pelajar yang mengikuti kursus Teknologi Maklumat Dakwah pada sem 


\section{THE EFFECTIVENESS OF THE ASSIGNMENT OF DIALOGUE}

1, 2013/14. Soalan dikemukakan dalam bentuk skala likert untuk mengesahkan keberkesanan tugasan yang diberikan secara maya dalam berdialog kepada kumpulan murtad dan Syiah. Metode ini digunakan sesuai dengan objektif kajian iaitu untuk mendapat maklum balas yang lebih mendalam tentang keberkesanan P\&P yang telah mereka lalui. Objektif kajian ialah untuk menganalisis dinamika tugasan yang diberikan, mengkaji aktiviti dan pola penggunaan media baharu dalam dialog dan menganalisis kelancaran tugasan.

\section{Dinamika Tugasan}

Pelajar telah diberi tugasan untuk berdialog dengan dua kumpulan yang berbeza pandangan dalam Islam meliputi Syiah dan Murtadin. Kajian ini akan mengkaji maklum balas mereka bagi menilai dinamika tugasan yang diberikan kepada mereka. Berikut adalah dapatan dari penilaian berkenaan.

Jadual 1: Penilaian Tugasan Kursus PPPM3033

\begin{tabular}{|c|c|c|c|c|c|c|c|c|}
\hline \multirow[t]{2}{*}{ Bil } & \multirow{2}{*}{$\begin{array}{l}\text { Penilaian } \\
\text { PPPM3033 }\end{array}$} & \multicolumn{5}{|c|}{ Peratus (\%) } & \multirow[t]{2}{*}{ Min } & \multirow[t]{2}{*}{ S.P. } \\
\hline & & STS & $\mathrm{TS}$ & TP & $\mathbf{S}$ & SS & & \\
\hline B1 & $\begin{array}{l}\text { Saya pernah berinteraksi secara maya } \\
\text { dengan golongan anti Islam }\end{array}$ & 0.0 & 0.0 & 6.0 & 20.0 & 74.0 & 4.68 & 0.59 \\
\hline B2 & $\begin{array}{l}\text { Saya rasa tugasan kursus PPPM3033 } \\
\text { adalah mencabar }\end{array}$ & 0.0 & 2.0 & 10.0 & 70.0 & 18.0 & 4.04 & 0.61 \\
\hline B3 & $\begin{array}{l}\text { Hujah dan provokasi kumpulan anti } \\
\text { Islam sangat hebat }\end{array}$ & 0.0 & 8.0 & 18.0 & 68.0 & 6.0 & 3.72 & 0.70 \\
\hline B4 & $\begin{array}{l}\text { Saya dapat berinteraksi secara } \\
\text { interaktif dengan mereka }\end{array}$ & 0.0 & 10.0 & 20.0 & 64.0 & 6.0 & 3.66 & 0.75 \\
\hline B5 & $\begin{array}{l}\text { Saya telah berjaya mematahkan hujah } \\
\text { mereka }\end{array}$ & 0.0 & 6.0 & 52.0 & 38.0 & 4.0 & 3.40 & 0.67 \\
\hline B6 & $\begin{array}{l}\text { Saya merasakan tugasan seperti ini } \\
\text { perlu diteruskan pada masa akan } \\
\text { datang }\end{array}$ & 0.0 & 0.0 & 2.0 & 36.0 & 62.0 & 4.60 & 0.54 \\
\hline B7 & $\begin{array}{l}\text { Saya rasa tugasan kursus PPPM } \\
\text { adalah sangat sesuai dilaksanakan } \\
\text { kepada pelajar JPDK }\end{array}$ & 0.0 & 0.0 & 0.0 & 38.0 & 62.0 & 4.62 & 0.49 \\
\hline B8 & $\begin{array}{l}\text { Saya rasa tugasan kursus PPPM } 3033 \\
\text { menjadikan pelajar lebih berani untuk } \\
\text { berdebat dengan golongan anti Islam }\end{array}$ & 0.0 & 2.0 & 12.0 & 68.0 & 18.0 & 4.02 & 0.62 \\
\hline
\end{tabular}

Sumber: Soal Selidik 2014

STS - Sangat Tidak Setuju TS - Tidak Setuju TP - Tidak Pasti S - Setuju SS - Sangat Setuju 


\section{THE EFFECTIVENESS OF THE ASSIGNMENT OF DIALOGUE}

Berdasarkan Jadual 4.7, kebanyakan pelajar merasakan bahawa tugasan berdialog adalah tugasan yang sangat mencabar keupayaan mereka sebagaimana dalam Soalan B2, dengan min 4.04. Mungkin ini adalah pengalaman baru bagi mereka kerana sebelum ini mungkin tidak pernah berdialog secara serius dengan aliran yang bertentangan dengan mereka. Oleh sebab itu, tidak hairanlah sekira ramai yang merasakan kurang boleh meyakinkan rakan dialog dengan Islam seperti dalam soalan B5 dengan min 3.40. Ini mungkin kerana keupayaan berdialog secara berhikmah belum lagi dapat dibangunkan dengan baik dalam kalangan pelajar. Biarpun mereka adalah tahun 3 yang juga tahun akhir tetapi kemampuan berdialog dengan berkesan bukanlah boleh dibangunkan dalam sehari dua, tetapi ia turut melibatkan proses kematangan pelajar. Ini kerana rakan dialog mereka adalah orang yang memang sudah pakar di dalam bidang mereka manakala mereka pula boleh dianggap sebagai orang yang baru mencari pengalaman. Walau bagaimanapun, matlamat dialog bukanlah untuk mencari menang atau kalah, kerana menang dalam perdebatan tidak semestinya lawannya itu akan mengikutinya. Selepas tewas dalam pentas perdebatan, dia tidak akan berasa kalah dan terus berusaha mencari kelemahan untuk menjatuhkan lawannya pula. Oleh sebab itu, menurut al-Bayanuni (1999), tujuan pendakwah bukanlah untuk berbalah bagi memperoleh kemenangan, mencari musuh atau untuk menjadi masyhur tetapi tujuannya adalah untuk menyampaikan dakwah Allah. Segala bukti lojik yang kukuh dikemukakan dan terpulang kepada rakan dialog untuk menerima atau sebaliknya kerana hidayah adalah milik Allah.

Namun, biarpun rata-rata pelajar merasakan tugasan ini mencabar, tetapi mereka setuju untuk tugasan ini diteruskan lagi pada masa akan datang seperti dalam B7 dengan 4.62. Ini kerana tugasan ini boleh melatih para pelajar berani mengeluarkan hujah yang bernas dalam berhadapan kumpulan yang berbeza pandangan dengan mereka secara ilmiah seperti yang ditunjukkan dalam B8, dengan min 4.02. Mungkin ini pengalaman pertama mereka terpaksa menggunakan segala ilmu dan pengalaman mereka untuk berdialog dan mereka benar-benar teruji dengan tugasan ini. Tugasan ini boleh melepasi tahap ketiga Bloom Taxonomy kerana ilmu yang ada pada pelajar teruji dan mereka boleh untuk berdialog biarpun belum mempunyai pengalaman. 


\section{THE EFFECTIVENESS OF THE ASSIGNMENT OF DIALOGUE}

\section{Aktiviti dan pola penggunaan media baharu dalam dialog}

Ketika berdialog, pelajar mempunyai masa untuk berfikir dan berbincang sebelum memberi maklum balas kerana dialog mereka menggunakan konsep asynchronous atau secara bertangguh. Konsep ini merujuk kepada dialog yang tidak mesti memberi maklum balas secara segera. Ia tidak terikat dengan sebarang tempat dan masa di mana mereka bebas untuk memberikan maklum balas, malahan mungkin sahaja mereka mengabaikan mesej dari rakan dialog mereka. Masa yang ada itu boleh digunakan untuk membuat rujukan, berfikir dan bertanya kepada orang lain sebelum membalas. Ia berbeza dengan dialog secara synchronous di mana komunikasi itu berlaku secara terus dan peserta dialog terus memberikan maklum balas tanpa bertangguh. Contohnya dialog secara bersemuka atau menerusi perbualan telefon yang memaksa kedua-dua belah pihak memberikan maklum balas segera. Komunikasi di dalam Facebook biasanya dijalankan dengan cara asynchronous kerana pengguna Facebook bebas untuk memberikan maklum balas pada bila-bila masa. Berikut adalah Jadual 2 yang menerangkan aktiviti dan pola penggunaan media baharu dalam berdialog.

Jadual 2: Aktiviti dan Pola Penggunaan Media Baharu dalam Berdialog

\begin{tabular}{|c|c|c|c|c|c|c|c|c|}
\hline \multirow[t]{2}{*}{ Bil } & \multirow[t]{2}{*}{ Aktiviti dan Pendekatan Pelajar } & \multicolumn{5}{|c|}{ Peratus (\%) } & \multirow[t]{2}{*}{ Min } & \multirow{2}{*}{$\begin{array}{l}\text { S.P } \\
.\end{array}$} \\
\hline & & STS & TS & TP & $\mathbf{S}$ & SS & & \\
\hline $\mathrm{C} 1$ & $\begin{array}{l}\text { Saya banyak mencari maklumat } \\
\text { berkaitan isu Syiah dan Murtad. }\end{array}$ & 0.0 & 0.0 & 4.0 & 74.0 & 22.0 & 4.18 & $\begin{array}{l}0.4 \\
8\end{array}$ \\
\hline $\mathrm{C} 2$ & $\begin{array}{l}\text { Saya membuat rujukan yang cukup } \\
\text { daripada internet sebelum } \\
\text { berinteraksi dengan kumpulan } \\
\text { Syiah dan Murtad. }\end{array}$ & 0.0 & 16.0 & 10.0 & 48.0 & 26.0 & 3.84 & $\begin{array}{l}0.9 \\
9\end{array}$ \\
\hline $\mathrm{C} 3$ & $\begin{array}{l}\text { Saya turut bertanya kepada } \\
\text { rakan-rakan dan pensyarah untuk } \\
\text { menjawab persoalan daripada } \\
\text { kumpulan Syiah dan Murtad. }\end{array}$ & 0.0 & 2.0 & 8.0 & 72.0 & 18.0 & 4.06 & $\begin{array}{l}0.5 \\
9\end{array}$ \\
\hline $\mathrm{C} 4$ & $\begin{array}{l}\text { Saya mendapatkan bantuan dari } \\
\text { rakan-rakan dan pensyarah untuk } \\
\text { mendapatkan maklumat berkaitan } \\
\text { Syiah dan Murtad. }\end{array}$ & 0.0 & 2.0 & 4.0 & 76.0 & 18.0 & 4.10 & $\begin{array}{l}0.5 \\
4\end{array}$ \\
\hline $\mathrm{C} 5$ & $\begin{array}{l}\text { Saya sentiasa mendapatkan } \\
\text { sokongan daripada pensyarah dan } \\
\text { rakan-rakan sebelum berhujah } \\
\text { dengan kumpulan Syiah dan }\end{array}$ & 0.0 & 0.0 & 14.0 & 72.0 & 14.0 & 4.00 & $\begin{array}{l}0.5 \\
4\end{array}$ \\
\hline
\end{tabular}


THE EFFECTIVENESS OF THE ASSIGNMENT OF DIALOGUE

Murtad di Facebook

$\begin{array}{lllllllll}\text { C6 Saya mencari sumber maklumat di } & 0.0 & 6.0 & 18.0 & 70.0 & 6.0 & 3.76 & 0.6\end{array}$ dalam buku sebagai alternatif untuk mendapatkan idea ketika berhujah dengan kumpulan Syiah dan Murtad di Facebook

C7 Saya menggunakan perkataan yang berhemah ketika mengeluarkan hujah kepada kumpulan Syiah dan Murtad di Facebook

C9 Saya menggunakan pendekatan yang berhikmah semasa $\begin{array}{llllll}2.0 & 8.0 & 84.0 & 6.0 & 3.94 & 0.4\end{array}$ mematahkan hujah kumpulan Syiah dan Murtad.

C1 Saya menggunakan contoh-conto

0 yang bersesuaian sebagai bukti

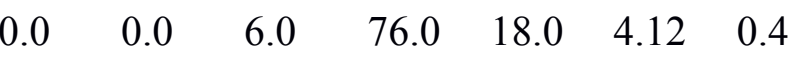
untuk menolak hujah daripada kumpulan Syiah dan Murtad di Facebook

Sumber : Soal Selidik 2014

STS $=$ Sangat Tidak Setuju TS $=$ Tidak Setuju TP $=$ Tidak Pasti $\mathbf{S}=$ Setuju $\mathbf{S S}=$ Sangat Setuju

Berdasarkan Jadual 2, kebanyakan mereka bersetuju bahawa mereka banyak mencari maklumat berkaitan isu Syiah dan Murtad seperti dalam item $\mathrm{C} 1$ dengan min 4.18. Ini bermakna mereka sudah cukup terdedah dengan maklumat yang berkaitan dan tidak menjadi suatu kejanggalan apabila tugasan ini diberikan kepada mereka. Sewaktu berdialog pula, para pelajar telah membuat persediaan yang baik. Ada di kalangan mereka yang bertanya dengan rakan-rakan dan pensyarah (item C4 dengan min 4.06), ada pula yang menggunakan Internet sebagai sumber maklumat (C2 dengan min 3.84) dan mencari maklumat di dalam buku (C6 dengan min 3.76). Dapatan ini menunjukkan bahawa perbincangan menerusi rakan-rakan dan pensyarah lebih banyak berbanding dengan medium yang lain terutamanya dengan membaca buku.

Dari sudut Bloom Taxonomy, tugasan berdialog ini boleh mengaktifkan pelajar untuk mencari sendiri maklumat sama ada dari sumber rakan, pensyarah, sumber internet atau pun buku. Mereka terpaksa mencari sendiri kerana tanpa bahan mereka tidak dapat berdialog atau tidak dapat memberikan idea yang bernas. Sekiranya mereka ingin menguasai dialog itu, 


\section{THE EFFECTIVENESS OF THE ASSIGNMENT OF DIALOGUE}

mereka memerlukan kepada pembacaan yang luas di dalam topik berkenaan. Mereka boleh berbincang sesama mereka, cuma kebimbangannya ialah apabila mereka membuat tafsiran yang salah yang akan menjurus kepada kefahaman yang sesat. Ia akan menyebabkan kepada penyebaran salah faham dan pegangan yang salah disampaikan kepada rakan dialog.

Semasa dialog pula, mereka merasakan bahawa mereka menggunakan pendekatan yang berhemah (3.92), dengan kata lain menggunakan pendekatan yang rasional, bukan secara emosi. Ini memang ditekankan di dalam dialog kerana pendekatan emosi akan membawa kesan yang tidak baik. Pendakwah perlu boleh mengawal emosi dan tahan provokasi kerana apabila teremosi dikhuatiri ia tidak akan dihormati.

\section{Kelancaran tugasan dialog maya}

Melaksanakan dakwah menerusi medium maya merupakan tugasan yang mencabar dan halangannya pun sungguh hebat. Pendakwah terpaksa berhadapan dengan hujah-hujah dari pihak yang tidak suka kepada Islam. Jadual 3 akan menjelaskan tentang kelancaran tugasan menjalankan dialog secara maya dengan kumpulan yang bertentangan.

Jadual 3: Kelancaran Tugasan Dialog Maya

\begin{tabular}{|c|c|c|c|c|c|c|c|c|}
\hline \multirow[t]{2}{*}{ Bil } & \multirow{2}{*}{$\begin{array}{l}\text { Keberkesanan } \\
\text { Cabaran/halangan }\end{array}$} & \multicolumn{5}{|c|}{ Peratus (\%) } & \multirow[t]{2}{*}{ Min } & \multirow[t]{2}{*}{ S.P. } \\
\hline & & STS & TS & TP & $\mathrm{S}$ & SS & & \\
\hline D1 & $\begin{array}{l}\text { Saya masih lagi meneruskan } \\
\text { interaksi dengan mereka walaupun } \\
\text { sudah selesai mengikuti kursus } \\
\text { PPPM3033 }\end{array}$ & 10.0 & 52.0 & 30.0 & 8.0 & 0.0 & 2.36 & 0.77 \\
\hline D2 & $\begin{array}{l}\text { Saya berasa yakin untuk } \\
\text { menegeluarkan hujah kepada } \\
\text { kumpulan Syiah dan Murtad selepas } \\
\text { melakukan tugasan PPPM3033 }\end{array}$ & 0.0 & 4.0 & 20.0 & 72.0 & 4.0 & 3.76 & 0.59 \\
\hline D4 & $\begin{array}{l}\text { Saya mampu menghadapi hujah dan } \\
\text { persoalan daripada kumpulan Syiah, } \\
\text { dan Murtad yang akan dikeluarkan }\end{array}$ & 0.0 & 4.0 & 60.0 & 36.0 & 0.0 & 3.32 & 0.55 \\
\hline D5 & $\begin{array}{l}\text { Saya mampu mengalahkan } \\
\text { kumpulan Syiah dan Murtad } \\
\text { berdasarkan hujah yang diberikan }\end{array}$ & 0.0 & 4.0 & 50.0 & 46.0 & 0.0 & 3.42 & 0.58 \\
\hline D6 & $\begin{array}{l}\text { Saya mendapat banyak ilmu selepas } \\
\text { berhujah dengan kumpulan Syiah } \\
\text { dan Murtad di Facebook }\end{array}$ & 0.0 & 0.0 & 10.0 & 56.0 & $\begin{array}{l}34 . \\
0\end{array}$ & 4.24 & 0.63 \\
\hline D7 & $\begin{array}{llr}\text { Saya rasa internet merupakan } \\
\text { medium yang sesuai untuk } \\
\text { mengekang dakyah kumpulan }\end{array}$ & 0.0 & 2.0 & 30.0 & 52.0 & $\begin{array}{l}16 . \\
0\end{array}$ & 3.82 & 0.72 \\
\hline $1^{\text {st }} I$ & rnational Conference on Islamic Education & & & & & & & 12 \\
\hline
\end{tabular}


THE EFFECTIVENESS OF THE ASSIGNMENT OF DIALOGUE

dan Murtad

\begin{tabular}{|c|c|c|c|c|c|c|c|}
\hline $\begin{array}{lll}\text { Saya berasa mudah } & \text { apabila } \\
\text { berinteraksi dua hala } & \text { dengan } \\
\text { golongan Syiah dan } & \text { Murtad } \\
\text { menerusi maya } & & \end{array}$ & 0.0 & 22.0 & 30.0 & 46.0 & 2.0 & 3.28 & 0.83 \\
\hline $\begin{array}{l}\text { Saya rasa semakin mahir untuk } \\
\text { menggunakan komunikasi secara } \\
\text { maya terhadap kumpulan Syiah dan } \\
\text { Murtad di Facebook }\end{array}$ & 0.0 & 2.0 & 28.0 & 70.0 & 0.0 & 3.68 & 0.51 \\
\hline $\begin{array}{l}\text { Saya tahu untuk mengaplikasikan } \\
\text { maklumat yang diperolehi untuk } \\
\text { mematahkan hujah kumpulan Syiah } \\
\text { dan Murtad di Facebook }\end{array}$ & 0.0 & 0.0 & 16.0 & 66.0 & $\begin{array}{l}18 . \\
0\end{array}$ & 4.02 & 0.59 \\
\hline
\end{tabular}

Sumber : Soal Selidik 2014

STS $=$ Sangat Tidak Setuju TS $=$ Tidak Setuju TP $=$ Tidak pasti $\mathbf{S}=$ Setuju $\mathbf{S S}=$ Sangat Setuju

Berdasarkan kepada Jadual 3 di atas, ramai pelajar berpandangan bahawa mereka mendapat banyak ilmu berkaitan golongan berkenaan selepas berdialog dengan mereka seperti yang ditunjukkan dalam item D6 dengan min 4.24. Ini bermakna bahawa tugasan ini telah memberikan input yang baik kepada pelajar dari sudut peningkatan ilmu. Dapatan ini menunjukkan bahawa berdialog atau bermuzakarah apatah lagi dengan orang yang berbeza pandangan salah satu cara berkesan di dalam PnP. Ini dikukuhkan dengan dapatan soalan D2 yang mendapati mereka mengaku berasa lebih yakin dan bersedia untuk berinteraksi dengan kumpulan ini selepas mengikuti kursus ini dengan min 3.76. Ini kerana dialog memerlukan keupayaan untuk memahamkan maklumat dan hujah yang diberikan dan dalam masa yang sama berfikir untuk memberikan pandangan balas yang lebih meyakinkan. Ini memerlukan kemahiran yang memerlukan kepada aktiviti pembelajaran yang boleh mencapai lebih dari tahap ketiga Bloom Taxonomy untuk menilai hujah rakannya terutamanya tahap sintesis.

Memang usaha meyakinkan orang dengan Islam adalah mencabar apatah lagi mereka yang telah sedia berpegang sesuatu pandangan yang berbeza dengan Islam. Oleh sebab itu, tidak berapa ramai mereka yang berasa ada keupayaan ini dan dapatan menunjukkan min yang sederhana iaitu 3.32 bagi item D4 dan 3.42 bagi item D5. Dapatan ini bukanlah suatu yang negatif kerana mereka masih dianggap baru dalam dunia dialog dan rakan dialog itu 


\section{THE EFFECTIVENESS OF THE ASSIGNMENT OF DIALOGUE}

mungkin orang yang sudah cekap dan berpengalaman, namun mereka masih tetap mencuba. Sungguhpun demikian, tidak ramai yang masih meneruskan dialog selepas mengikuti kursus PM 3033 sebagaimana yang ditunjukkan dalam D1 dengan min yang sangat rendah itu 2.36. Mungkin pelajar merasakan tugasan ini agak mencabar dan terpaksa mengambil masa yang banyak untuk menyediakan bahan dialog dan memberikan maklum balas terhadap mesej yang disampaikan.

\section{PENUTUP}

Tugasan dialog maya ini merupakan suatu usaha yang boleh membawa kepada keberkesanan dalam PnP, apatah lagi sekiranya dialog dalam konteks pandangan yang berbeza sehingga membawa kepada perdebatan. Pelajar terpaksa memerah otak untuk mencari idea bagi memberikan maklum balas seperti mana yang ditunjukkan dalam hasil kajian ini. Ini memang boleh memberikan kesan kepada kemahiran kognitif yang secara tidak langsung mengasah kemahiran memberikan pandangan dengan kelompok yang berbeza. Kelebihan yang ada pada dialog maya ialah ruang masa yang tidak memerlukan kepada mereka untuk menjawab semua persoalan itu secara segera. Ini memberikan kepada pelajar ruang yang luas untuk belajar dan mengkaji serta menganalisis secara mendalam sebelum memberikan sebarang pandangan.

Pelajar yang ditugaskan untuk berdialog dengan kumpulan Syiah dan Murtad, merupakan orang yang tiada pengalaman dalam berdialog, apatah lagi secara maya. Mereka adalah orang baru yang berdialog kepada orang yang sudah lama dan ada pengalaman. Oleh sebab itu, mereka memerlukan kepada pembimbing yang boleh membimbing mereka meneruskan dialog dengan cara berkesan. Peranan pembimbing ini sangat penting kerana pelajar boleh dianggap masih mentah lagi dalam berhadapan dengan orang yang sudah lama dan sangat berpengalaman. 


\section{THE EFFECTIVENESS OF THE ASSIGNMENT OF DIALOGUE}

\section{RUJUKAN}

Aclan, E. M., Aziz, A., Hashima, N., \& Valdez, N. P. (2016). Debate as a pedagogical tool to develop soft skills in EFL/ESL classroom: A qualitative case study. Pertanika Journal of Social Sciences \& Humanities, 24(1).

Annamalai, N., Tan, K. E., \& Abdullah, A. (2016). Teaching presence in an online collaborative learning environment via facebook. Pertanika Journal of Social Sciences \& Humanities, 24(1).

Al-Bayanuni, Muhammad Abu al-Fath. (1999). Al-Madkhal ila 'ilm al-Da'wah. Bayrut: Muasssat al-Risalah.

Buku Panduan Pra-siswazah (2013).

al-Ghadban, Munir Muhammad. (2011). Al-Hiwar, Syariat, wa waqi'an, wa tarikhan. Al-Qahirah: Dar al-Salam.

Long Alex Lai, I. (2005). Knowledge management for Chinese medicines: a conceptual model. Information Management \& Computer Security, 13(3), 244-255.

Muhamad Faisal Ashaari, \& Nur Adhwa Farahin Saparudin. (2012). Kriteria newsworthiness dalam entri Facebook dakwah. Islamiyyat: Jurnal Antarabangsa Pengajian Islam, 34, $45-51$

Whiteley, T. R. (2014). Using the socratic method and Bloom's taxonomy of the cognitive domain to enhance online discussion, critical thinking, and student learning. Developments in Business Simulation and Experiential Learning, 33. 